\title{
Оценка доверия жителей Санкт-Петербурга к использованию электронных каналов взаимодействия с властью
}

\author{
Л.А. Видясова, Я.Д. Тенсина \\ Университет ИТМО \\ bershadskaya.lyudmila@gmail.com, tensina.yaroslava@mail.ru
}

\section{Аннотация}

В статье представлены результаты опроса жителей Санкт-Петербурга о доверии к информационным технологиям. Проведенное исследование предлагает подход к изучению киберсоциального доверия в сфере G2C взаимодействия, обнаруженного в развитии электронного правительства, предоставлении электронных государственных услуг и электронном участии в управлении городом.

В ходе исследования было проведено анкетирование 600 жителей Санкт-Петербурга с целью оценки доверия к новым технологиям, используемым для общения с органами власти и получения государственных услуг, решения городских проблем и участия в управлении городом. Результаты опроса показали высокий уровень использования Интернета, а также повышение уровня доверия к финансовым транзакциям через Интернет. В то же время, был отмечен низкий уровень доверия граждан к взаимодействию с органами власти в электронном формате, а также низкий уровень доверия к Интернет-порталам для решения городских проблем.

Ключевые слова: социальное доверие, киберсоциальное доверие, информационные технологии, электронное участие

Библиографическая ссылка: Видясова Л.А., Тенсина Я.Д. Оценка доверия жителей Санкт-Петербурга к использованию электронных каналов взаимодействия с властью // Государство и граждане в электронной среде. Выпуск 3 (Труды XXII Международной объединенной научной конференции «Интернет и современное общество», IMS-2019, Санкт-Петербург, $19-22$ июня 2019 г. Сборник научных трудов). - СПб: Университет ИТМО, 2019. С. 93 - 101. DOI: 10.17586/2541-979X-2019-3-93-101

\section{1. Введение}

В настоящее время становится очевидным, что использование новых технологий влечет за собой определенные преобразования доверия в институте общественных коммуникаций. В связи с этим определение границ возможного проникновения технологий в жизнь людей приобретает большое значение, а проблематизация киберсоциального доверия приобретает особую актуальность. Киберсоциальное доверие отражает специфику отношения людей к функционированию сложных информационных систем, в том числе элементов искусственного интеллекта.

В течение долгого времени проблема распространения и использования Интернета рассматривалась с технологической точки зрения готовности цифровой инфраструктуры или с точки зрения навыков и знаний, которыми должны обладать люди. В то же время практика показывает неадекватность такого подхода и необходимость понимания «цифрового разрыва» не только с точки зрения способностей граждан, но и с точки зрения их осознанного выбора, одним из мотивов которого является доверие в технологии. Таким образом, проблема использования / неиспользования технологии оказывается связанной с 
проблемами доверия к технологиям, межличностного доверия и институционального доверия к средствам массовой информации, государственным институтам, бизнес-игрокам и другим субъектам.

В научной литературе отмечается, что доверие является фундаментальным аспектом информационно-компьютерных социальных взаимодействий и технологическое развитие зависит от двух основных факторов: развитие технологии, определяемое уровнем технологических знаний, и адаптация и принятие технологии обществом [1]. А. Киран и П. Вербек отмечают, что вместо того, чтобы с недоверием относиться к технологиям, сложные связи между человечеством и технологией побуждают нас развивать способность активно доверять себя технологии [2].

Доверие к технологиям можно определить, как готовность человека быть подверженным/восприимчивым к информационным технологиям (ИТ), основанную на ожиданиях предсказуемости технологии, ее надежности и полезности, а также индивидуального предпочтения технологии [3]. Доверие является одной из основ, определяющих уровень принятия и использования технологий, часто отражаемых в моделях их принятия $[4,5]$. Доверие к технологиям представляется важным в условиях неопределенности, непредсказуемости развития и все более сильной зависимости человека от них, а также является важным фактором, который снижает риски и неопределенности, связанные с использованием технологий $[6,7,8]$.

В международной практике имеются примеры исследований, оценивающих доверие и субъективные оценки рисков при использовании гражданами электронных услуг. Например, в исследовании Д. Моу, Д. Шин и Д. Кохен [9] было подтверждено, что уровень доверия в большей степени влияет на использование электронных услуг, нежели чем субъективное чувство риска. В случае с использованием государственных услуг и участием посредством электронных площадок в городском управлении, было выявлено, что низкий уровень принятия и использования услуг электронного правительства конечными пользователями остается основным препятствием на пути к успешному внедрению электронного правительства и это может быть решено путем повышения доверия к правительству, Интернету и технологиям [10, 11].

В данной статье представлены результаты опроса населения Санкт-Петербурга, целью которого является выявление уровня доверия к новым технологиям для взаимодействия с властью и участия в управлении городом.

\section{2. Методология исследования}

В проведенном исследовании феномен доверия концептуально рассматривается в институциональном контексте политической сферы и выражается в оценке доверия / недоверия граждан к использованию информационных технологий для взаимодействия с представителями правительства через электронные порталы, формы электронных обращений, получения электронных услуг, электронного голосования и др.

Исследование направлено на выявление уровня социального доверия к новым технологиям в Санкт-Петербурге. Для опроса жителей Санкт-Петербурга был использован метод анкетирования. Данные были получены интервьюерами в ходе личного опроса. В качестве места для проведения исследования были выбраны 6 многофункциональных центров (МФЦ), предоставляющих государственные и муниципальные услуги. Важно отметить, что эти МФЦ расположены в густонаселенных районах города.

Для расчета выборочной совокупности использовались данные о численности населения, его возрастном и половом составе. Данные получены на официальном сайте Управления Федеральной службы статистики по Санкт-Петербургу и Ленинградской области. На основании данных о численности населения в целом был рассчитан размер выборки - 600 респондентов. Ошибка выборки не превышает 4\%, уровень достоверности составил $95 \%$. 
Опрос был проведен в ноябре 2018 года. В исследовании приняли участие шестьсот граждан, которые были разделены на шесть возрастных групп: 18-25 лет, 26-35 лет, 36-45 лет, 46-55 лет, 56- 65 лет и старше 65 лет (см. Таблицу 1).

Таблица 1. Распределение респондентов по возрасту, 2018

\begin{tabular}{|c|c|}
\hline Возрастная группа & $\begin{array}{c}\text { Доля от общего количества } \\
\text { респондентов, \% }\end{array}$ \\
\hline $18-25$ лет & 15 \\
$26-35$ лет & 19 \\
$36-45$ лет & 17 \\
$46-55$ лет & 18 \\
$56-65$ лет & 16 \\
старше 65 лет & 16 \\
\hline
\end{tabular}

В каждой возрастной группе было рассчитано процентное соотношение мужчин и женщин: в исследовании приняли участие 43\% мужчин и 57\% женщин. Анализ распределения респондентов по профессиям показал, что большинство являются служащими / специалистами (39\%), рабочими / охранниками / водителями (20\%) и студентами (10\%).

В исследовании были изучены вопросы электронного взаимодействия граждан и власти, означающее систему взаимообусловленных социальных действий, при которой действия одного субъекта одновременно являются причиной и следствием ответных действий других субъектов. Взаимодействие власти и граждан рассматривается в данной статье в трех предметных областях: получение электронных государственных услуг, решение городских проблем посредством электронных площадок и электронное участие в управлении городом.

В соответствии с целью исследования вопросы в анкете были составлены таким образом, чтобы получить информацию по следующим вопросам:

- доверие новым технологиям для взаимодействия с органами власти и получения государственных услуг;

- доверие новым технологиям для решения городских проблем;

- доверие новым технологиям для участия в управлении городом.

\section{3. Результаты исследования}

Результаты опроса показали, что большинство жителей Санкт-Петербурга являются активными пользователями Интернета. Большинство респондентов отметили, что они используют Интернет каждый день (42\%) или почти всегда онлайн (26\%). Результаты опроса также показывают, что большинство респондентов определяют себя как довольно опытных пользователей информационных технологий, но самостоятельно осваивать новые программы сложно (32\%). В то же время 29\% респондентов отметили, что могут легко освоить новые программы, приложения и продукты.

В ходе исследования было выявлено, что большинство жителей Санкт-Петербурга в первую очередь доверяют использованию новых технологий, когда необходимо оплатить некоторые услуги через Интернет (45\%) (см. рис. 1). Большинство из этих респондентов принадлежали к возрастным группам «26-35 лет» (25\%) и «18-25 лет» (24\%), а часть респондентов, выразивших недоверие к этому способу оплаты, принадлежала группе «старше 65 лет» $(48 \%)$.

Наименьший процент респондентов указали, что они полностью доверяют использованию новых технологий для общения с властями и их представителями через свои официальные страницы в социальных сетях (15\%). Стоит отметить, что жители Санкт- 
Петербурга больше выражают доверие к получению государственных услуг через Интернет (45\%), а также к подаче электронных заявок (41\%) и электронных петиций $(38 \%)$.

Наибольшее недоверие граждан выразили за общение с властями и их представителями через их официальные страницы в социальных сетях (30\%). Большинство из этих респондентов относятся к возрастным группам «старше 65 лет» $(29 \%)$ и «56-65 лет» $(21 \%)$. Также респонденты отметили, что они скорее не доверяют голосованию за / против электронных обращений или петиций (29\%).

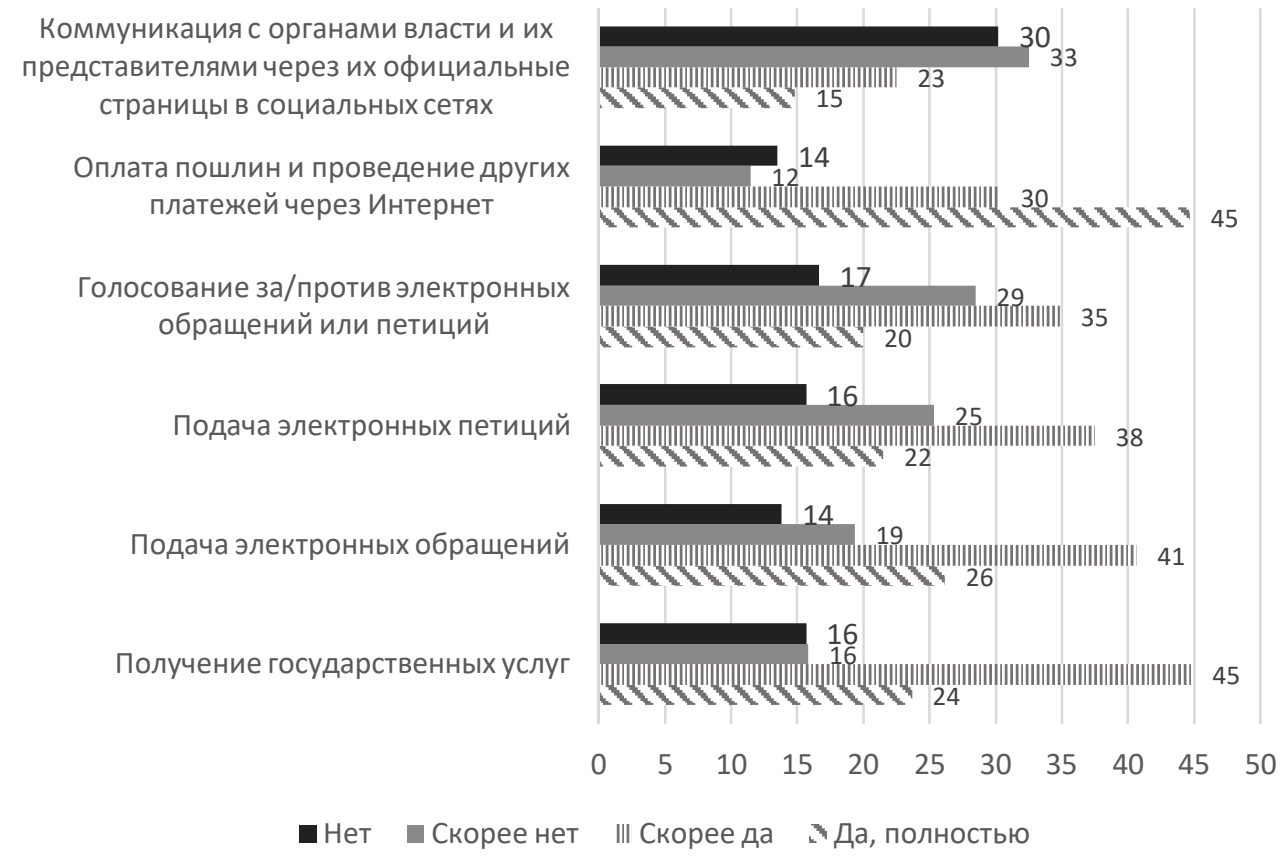

Рис. 1. Распределение ответов респондентов на вопрос «Доверяете ли Вы информационным технологиям (Интернет, мобильные приложения и т.д.) как средству взаимодействия в перечисленных ситуациях?», \%
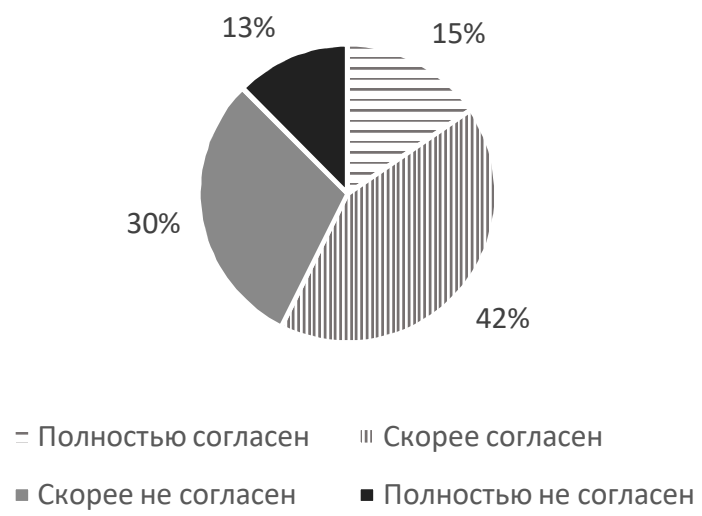

Рис. 2. Распределение ответов респондентов на вопрос «Согласны ли Вы с утверждением «По мере того, как расширяется использование Интернета в целом, органы власти уделяют больше внимания реагированию на запросы граждан, поступающие в ИОГВ» (становятся более отзывчивыми к гражданам, более внимательными к проблемам граждан и т.д.)?» 
Результаты опроса показывают, что большинство жителей Санкт-Петербурга согласились с тем, что с расширением Интернета власти уделяют больше внимания реагированию на запросы граждан (становятся более отзывчивыми к гражданам, более внимательными к проблемам граждан) (42\%) (см. рис. 2). В то же время, 1/3 респондентов не согласились с этим утверждением (30\%). Важно отметить, что респонденты, которые склонны доверять вниманию властей к проблеме граждан, в основном относятся к молодой возрастной группе «26-35 лет» (28\%). Наибольшее недоверие было выражено в группе «65 лет +» $(36 \%)$.

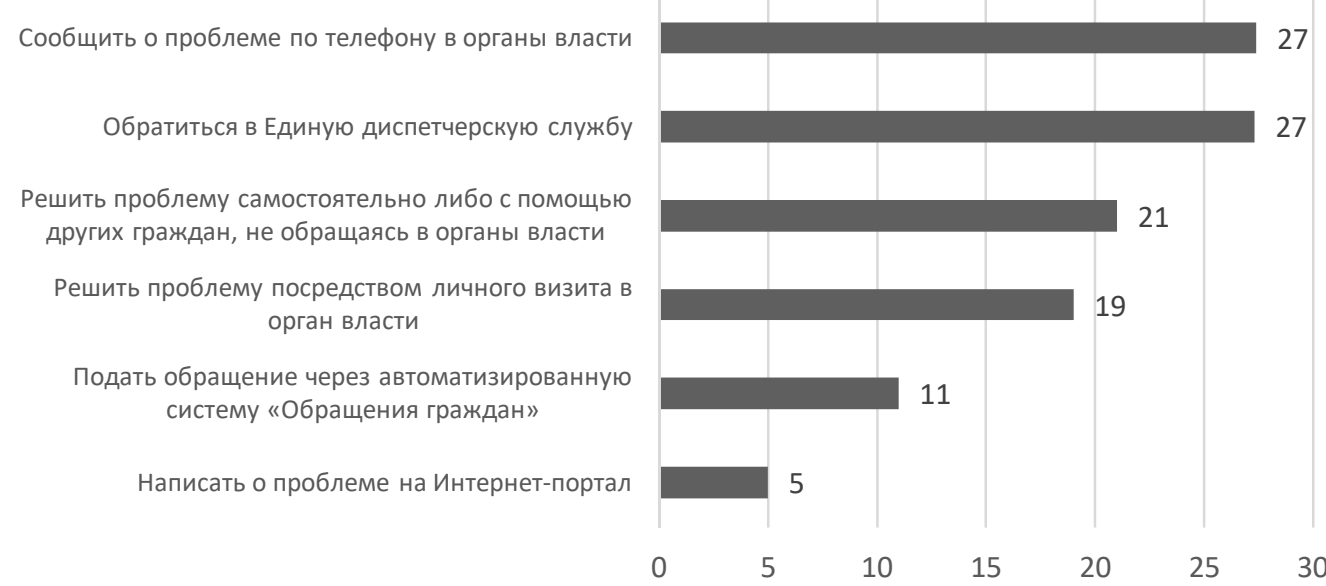

Рис. 3. Распределение ответов респондентов на вопрос «Какой способ решения городских проблем в Петербурге Вы считаете самым эффективным?», \%

Большинство опрошенных жителей Санкт-Петербурга отметили, что наиболее эффективным способом решения городских проблем в Санкт-Петербурге является сообщение о проблеме властям по телефону (27\%) (см. Рис. 3). Граждане считают личный визит в органы государственной власти более эффективным способом решения проблем (19\%), в то время как доля граждан, которые верят в эффективность Интернет-порталов, остается незначительной $(5 \%)$.

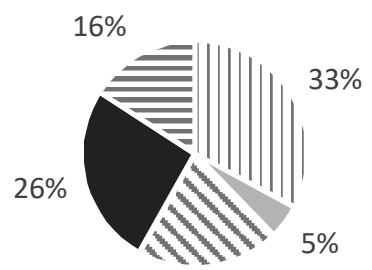

$20 \%$

I Да, и это позитивный опыт (удовлетворен использованием)

घ Да, и это негативный опыт

- Не имею опыта, но хотел бы попробовать

- Не имею опыта и не хочу пробовать

- Затрудняюсь ответить

Рис. 4. Распределение ответов респондентов на вопрос «Имеете ли Вы лично опыт обращения в органы государственной власти через электронные приемные?» 
Результаты опроса показали, что большинство респондентов имели положительный опыт общения с государственными органами через электронные приемные (33\%) (см. рис. 4). Доля респондентов, имевших негативный опыт, остается незначительной (5\%). Важно отметить, что респонденты, которые имели положительный и отрицательный опыт, относятся к одной и той же возрастной группе «26-35 лет»: 27\% были удовлетворены использованием электронных приемов, а 34\% столкнулись с некоторыми трудностями. Отсутствие опыта, но заинтересованность в использовании электронного приема было в основном выражено респондентами самой молодой группы «18-25 лет» (24\%).

Большинство респондентов имеют положительный опыт использования порталов государственных услуг. Более половины респондентов удовлетворены использованием Единого Портала Государственных и Муниципальных Услуг (www.gosuslugi.ru) (54\%), a также имеют положительный опыт работы с Порталом Государственных и Муниципальных услуг Санкт-Петербурга (www.gu.spb.ru) (38\%).

В то же время жители Санкт-Петербурга не активно используют порталы электронного участия. Большинство респондентов отметили, что никогда не пользовались региональным порталом «Наш Санкт-Петербург» (https://gorod.gov.spb.ru/) и не хотят пробовать (45\%) (см. рис. 5). Аналогичные результаты были получены для порталов «Change.org» (https://www.change.org/) (47\%) и «Российская общественная инициатива» (https://www.roi.ru/) (51\%). Процент респондентов, имеющих положительный опыт использования этих порталов, варьируется от 5\% до 13\%.

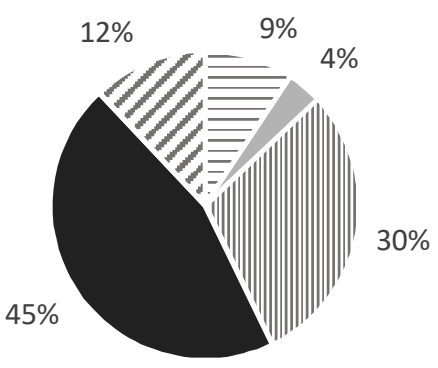

\author{
- Да, и это позитивный опыт (удовлетворен использованием) \\ - Да, и это негативный опыт \\ ॥ Не имею опыта, но хотел бы попробовать \\ - Не имею опыта и не хочу пробовать \\ - Затрудняюсь ответить
}

Рис. 5. Распределение ответов респондентов на вопрос «Имеете ли Вы лично опыт публикации обращения/ петиции на портале «Наш Петербург» либо участия в голосовании/ размещении комментариев и т.д. на этом портале?»

Полученные данные позволяют оценить текущий уровень использования информационных технологий в контексте трех типов взаимодействия граждан и власти: получение электронных услуг, использование порталов решения городских проблем и участие в городском управлении посредством соответствующих платформ. Кроме того, были выявлены субъективные оценки категории доверия к использованию информационных технологий в данных сферах. 


\section{Выводы}

Результаты исследования свидетельствуют о том, что серьезной предпосылкой для установления общественного доверия к новым технологиям является высокий уровень проникновения интернета среди жителей города. Усиление использования технологий в повседневной практике отражается на высоком уровне доверия к финансовым транзакциям в Интернете при оплате сборов и штрафов.

Официальные каналы получения электронных государственных услуг были высоко оценены респондентами. Однако в гораздо меньшей степени жители Санкт-Петербурга доверяют общению с представителями власти на официальных страницах в социальных сетях. Результаты опроса показали, что большинство респондентов имели положительный опыт общения с государственными органами через электронные системы. В то же время процент респондентов, которые не хотят пробовать использовать электронный канал для связи с государственными органами, выше, чем доля респондентов, которые хотели бы попробовать. Это может свидетельствовать о некотором исчерпании ресурсной базы для расширения электронного взаимодействия жителей Санкт-Петербурга с властями, т.е. большинство тех, кто готов использовать электронные средства для этих целей, их уже используют.

Результаты опроса показали, что большинство респондентов имеют положительный опыт использования порталов государственных услуг. Тем не менее, респонденты оценили телефонный звонок как эффективный способ решения городских проблем выше, чем использование специализированных Интернет-порталов для их решения. С одной стороны, такое положение вещей подчеркивает, что электронные услуги стали в некоторой степени обыденным явлением, а участие в работе площадок петиций и сборе обращений является выражением активной гражданской позиции. Недостаточная популярность подобных площадок объясняется также слабостью гражданского общества в современных российских реалиях. В то же время не высокий интерес к использованию новых технологий может быть обусловлен как низкой информированностью граждан об их возможностях, а также имеющимися ожиданиями рисков, связанных с их внедрением.

Практическая ценность исследования заключается в том, что в нем предпринята попытка эмпирически оценить использование электронных каналов взаимодействия $\mathrm{C} 2 \mathrm{G}$ между гражданами и государством, а также выявить потенциальные предпочтения их использования и неиспользования, если респондент еще не имел опыта доступа к ним.

Важным этапом для продолжения данной исследовательской линии авторы считают сравнение полученных данных о доверии информационным технологиями при взаимодействии с властью с общим уровнем доверия властным институтам и отдельным политическим лидерам, как на уровне страны, так и в регионах и муниципалитетах.

Дальнейшие исследования должны быть направлены на определение модели социального доверия для новых технологий, включая не только показатели субъективного восприятия, но и объективно измеренные параметры проявления доверия / недоверия к общению через Интернет в различных областях. Результаты построения многофакторных моделей позволят разработать новый концепт доверия информационным технологиями, а также ряд рекомендаций для разработчиков сервисов электронного взаимодействия граждан и власти.

Исследование выполнено за счет гранта Российского фонда фундаментальных исследований (проект № 18-311-20001 «Исследование киберсоциального доверия в контексте использования и отказа от информационных технологий»). 


\title{
Литература
}

[1] Nazarko J., Ejdys J., Halicka K., Magruk M., Nazarko Ł., Skorek A. Factor Analysis as a Tool Supporting STEEPVL Approach to the Identification of Driving Forces of Technological Innovation // Procedia Engineering. 2017. Vol. 182. P. 491-496.

[2] Kiran A. H., Verbeek P.-P. Trusting Our Selves to Technology // Knowledge, Technology \& Policy. 2010. Vol. 23 (3-4). P. 409-427.

[3] Lippert S.K. An Exploratory Study into the Relevance of Trust in the Context of Information Systems Technology. Doctoral Dissertation. Washington: The George Washington University, 2001.

[4] Muir B.M. Trust between humans and machines, and the design of decision aids // International Journal Man-Machine Studies. 1987. Vol. 27(5-6). P. 527-539.

[5] Wasiluk A. Trust and areas of cooperation between companies and institutions of science // Conference: 21st International Scientific Conference on Smart and Efficient Economy Preparation for the Future Innovative Economy Brno: Brno University of Technology, 2018. P. 629-636.

[6] Halicka K. Main Concepts of Technology Analysis in the Light of the Literature on the Subject // Procedia Engineering. 2017. Vol. 182. P. 291-298.

[7] Nazarko Ł. Future-Oriented Technology Assessment // Procedia Engineering. 2017. Vol. 182. P. 504-509.

[8] Ejdys J. Trust in Technology in Case of Humanoids Used for the Care for the Senior Persons // Multidisciplinary Aspects of Production Engineering - MAPE. 2018. Vol. 1 (1). P. 875-881.

[9] Mou J., Shin D-H, Cohen J.F. Trust and risk in consumer acceptance of e-services // Electronic Commerce Research. 2017. Vol. 2, № 17. P. 255-288.

[10] Benoit A., Fakhoury R. Citizenship, trust, and behavioral intentions to use public e-services: The case of Lebanon // International Journal of Information Management. 2015. Vol. 3, № 35. P. 346-351.

[11]Mõtlik A. Trust towards services of e-government: Master's thesis / Tallinn university of technology. Faculty of Information Technology, 2016. 105 p.

\section{Research of the trust of St. Petersburg residents in using electronic channels of interaction with the authorities}

\author{
L. Vidiasova, I. Tensina
}

\section{ITMO University}

The article presents the results of a survey of residents of St. Petersburg about trust in information technology. The study suggests an approach to the study of cyber-social trust in the field of G2C communications, found in the development of e-government, the provision of e-government services and e-participation in the management of the city.

In the course of the survey, 600 residents of St. Petersburg were surveyed to assess the level of trust in new technologies used to communicate with authorities and receive public services, solve urban problems and participate in the management of the city. The survey results showed a high level of Internet use, as well as an increase in confidence in financial transactions over the Internet. At the same time, there was a low level of citizens' trust in interacting with authorities in electronic format, as well as a low level of trust in Internet portals for solving urban problems.

Keywords: social trust, cyber social trust, information technology, e-participation

Reference for citation: Vidiasova L., Tensina I. Research of the trust of St. Petersburg residents in using electronic channels of interaction with the authorities // The State and Citizens in the 
Electronic Environment. Vol. 3 (Proceedings of the XXII International Joint Scientific Conference «Internet and Modern Society», IMS-2019, St. Petersburg, June 19-22, 2019). - St. Petersburg: ITMO University, 2019. P. 93 - 101. DOI: 10.17586/2541-979X-2019-3-93-101

\section{Reference}

[1] Nazarko, J., Ejdys, J., Halicka, K., Magruk, M., Nazarko, Ł., Skorek, A. Factor Analysis as a Tool Supporting STEEPVL Approach to the Identification of Driving Forces of Technological Innovation // Procedia Engineering, 2017, 182, pp. 491-496.

[2] Kiran A. H., Verbeek P.-P. Trusting Our Selves to Technology // Knowledge, Technology \& Policy, 2010, № 23 (3-4), pp. 409-427.

[3] Lippert, S.K. An Exploratory Study into The Relevance of Trust in the Context of Information Systems Technology. Doctoral Dissertation, Washington: The George Washington University.

[4] Muir, B.M. Trust between humans and machines, and the design of decision aids // International Journal Man-Machine Studies, 1987, 27(5-6), pp. 527-539.

[5] Wasiluk A. Trust and areas of cooperation between companies and institutions of science // Conference: 21st International Scientific Conference on Smart and Efficient Economy Preparation for the Future Innovative Economy Brno: Brno University of Technology, 2018, pp. 629-636.

[6] Halicka, K. Main Concepts of Technology Analysis in the Light of the Literature on the Subject // Procedia Engineering. 2017, 182, pp. 291-298.

[7] Nazarko, Ł. Future-Oriented Technology Assessment // Procedia Engineering, 2017, 182, pp. 504-509.

[8] Ejdys J. Trust in Technology in Case of Humanoids Used for the Care for the Senior Persons // Multidisciplinary Aspects of Production Engineering - MAPE, 2018, 1 (1), pp. 875-881.

[9] Mou J., Shin D-H, Cohen J.F. Trust and risk in consumer acceptance of e-services // Electronic Commerce Research. 2017. Vol. 2. No. 17. P. 255-288.

[10] Benoit A., Fakhoury R. Citizenship, trust, and behavioral intentions to use public e-services: The case of Lebanon // International Journal of Information Management. 2015. Vol. 3. No. 35. P. 346-351.

[11]Mõtlik A. Trust towards services of e-government: Master's thesis // Tallinn university of technology. Faculty of Information Technology. 2016. 105 p. 